\title{
Polyphenoxyl Radical Photochemically Generated from the Oxalate Derivative of Poly(1,2-phenylenevinylene)
}

\author{
Masahiro TAKAHASHI, Yasumasa NASU, Hiroyuki Nishide, ${ }^{\dagger}$ \\ and Eishun TsuCHIDA ${ }^{\dagger}$ \\ Depertment of Polymer Chemistry, Waseda University, Tokyo 169-8555, Japan
}

(Received August 18, 1998)

\section{KEY WORDS Polyradical / Poly(1,2-phenylenevinylene) / Photolysis / Bisaryloxalate /}

Recently, there has been substantial interest in synthesizing $\pi$-conjugated organic polyradicals which display intramacromolecular ferromagnetic spin alignment. ${ }^{1,2}$ One of these synthetic approaches focuses on $\pi$-conjugated polymers, such as polyacetylene and polyphenylenevinylene, bearing pendant radical groups, such as nitroxyl, phenoxyl, and galvinoxyl. ${ }^{1 \mathrm{~d}, 2 \mathrm{~b}, 2 \mathrm{~d}}$ In these polyradicals, the $\pi$-conjugated backbone and the pendant radicals share the roles of a ferromagnetic coupler and a spin source, respectively, and the spin multiplicity at ground state is expected to be proportional to the number of the generated radicals per one polymer molecule. ${ }^{3}$ We have succeeded in achieving ferromagnetic spin alignment for poly [4-(3',5'-di-t-butyl-4'-oxyphenyl)-1,2-phenylenevinylene] 1a; the poly(1,2-phenylenevinylene) bearing phenyloxy radical 1a displayed spinquantum number $S$ of $4 / 2$ to $5 / 2$ even with the radical (spin) concentration of $c a .0 .6 \mathrm{spin} /$ monomer unit. ${ }^{2 \mathrm{~b}}$ The radicals of these polymers have been generated by the chemical and heterogeneous oxidation of the precursor phenolic polymers with aqueous $\mathrm{K}_{3} \mathrm{Fe}(\mathrm{CN})_{6}$ or $\mathrm{PbO}_{2}$ powder. Thus the radical generation was incomplete for realizing the utmost $S$ which is comparable to the degree of polymerization.

A variety of unimolecular pathways are known to generate the aryloxyl radicals ${ }^{4-6}$ For example, bisaryloxalate, such as bis(2,4,6-tri-t-butylphenyl)oxalate $\mathbf{2}$, aryloxy oxalyl chloride, aryloxy oxalyl $t$-butyl peroxide, and $N$-(phenoxycarbonyloxy)-2-thiopyridone are photochemically cleaved to yield one or two aryloxyl radical(s) even under rigid phase conditions and/or at cryogenic temperature, as shown in Scheme 1. Such photochemical generation of aryloxyl radicals has been applied to

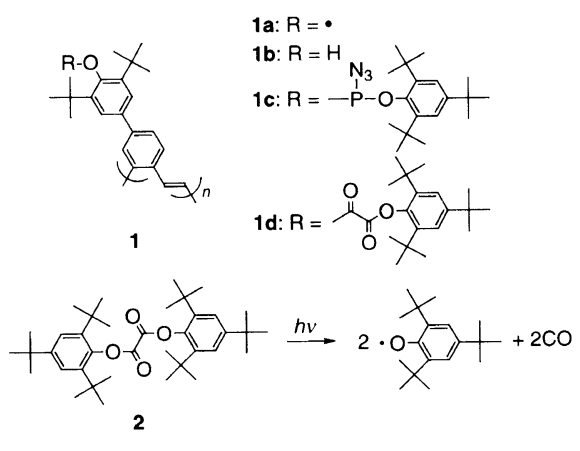

Scheme 1.

\footnotetext{
$\dagger$ To whom correspondence should be addressed.
}

polyphenoxyl radicals; poly(phenylacetylene) bearing bisaryloxalate by Lahti ${ }^{7}$ and poly(1,2-phenylenevinylene) bearing bisaryloxyphosphineazide 1c by us. ${ }^{8}$ In the latter 1c, we introduced the photo-cleavable bisaryloxyphosphineazide on poly(4-hydroxyphenyl-1,2-phenylenevinylene) $\mathbf{1 b}$ via a polymer reaction; $1 \mathbf{a}$ gave a strong absorption peak at $g=2$ and a forbidden transition at $g=4$ ascribed to triplet species in the ESR spectrum under the irradiation of a high-pressure xenon arc lamp even at low temperature and/or in the solid state. Although the phosphineazide fraction introduced on the polymer was limited to 0.7 due to a polymer reaction, the yield of the photochemically generated phenoxyl radical reached greater than 0.9 based upon the accessible number of photolysis group.

This study deals with the preparation and polymerization of the photo-cleavable bisaryloxalate derivative of bromostyrene and the photochemical generation of the polyphenoxyl radical in the solid phase or at low temperature. The polyradical displayed a multiplet ground state as has been reported for the chemically oxidized polyradicals.

\section{RESULTS AND DISCUSSION}

The bisaryloxalate derivative of 2-bromostyrene 5 was prepared as the monomer according to Scheme 2. 2Bromo-4-(3', $5^{\prime}$-di-t-butyl-4'-hydroxyphenyl)toluene $3^{2 \mathrm{~b}}$ and 2,4,6-tri- $t$-butylphenyloxalylchloride ${ }^{4}$ were reacted to yield the bisaryloxalate derivative 4 . The methyl group of $\mathbf{4}$ was converted to a vinyl group via benzylic bromination and the Wittig reaction to yield the bromostyrene derivative $\mathbf{5}$. The bromostyrene was linked with a head-to-tail vinylene bond via the arylation of an olefin with an aryl bromide by the Heck reaction. That

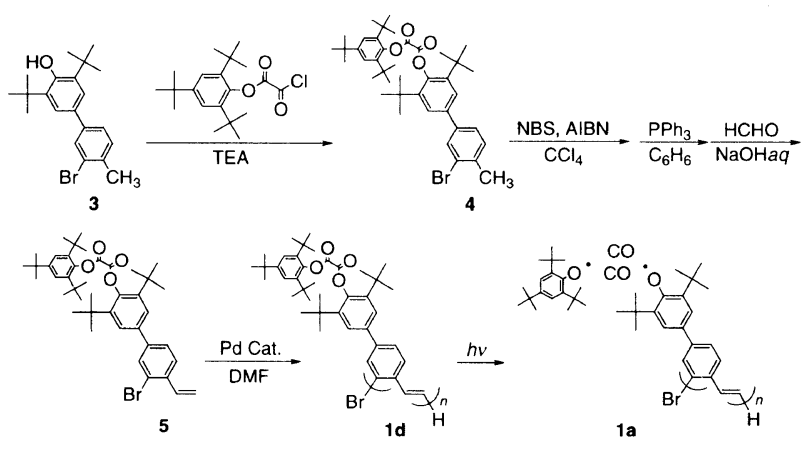

Scheme 2. 


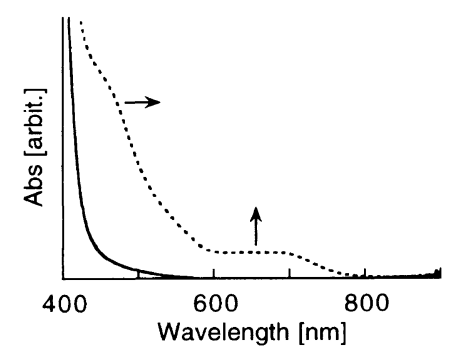

Figure 1. UV/Vis spectral change after the photo-irradiation on the thin film of 1d. The dashed and solid line for after and before the photo-irradiation, respectively.

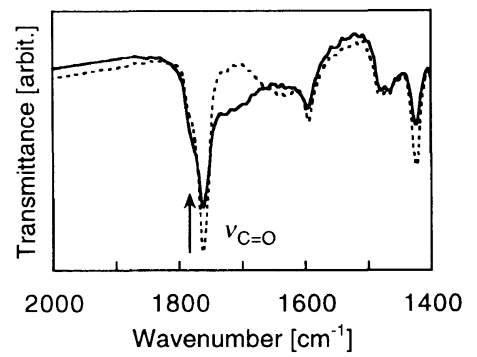

Figure 2. IR spectral change after the photo-irradiation on the thin film of 1d. The dashed and solid line for before and after the photo-irradiation, respectively.

is, 5 was polymerized using a palladium acetate and tri-o-tolylphosphine catalyst in the presence of triethyamine as a base in the $N, N$-dimethylformamide (DMF) solution at $100^{\circ} \mathrm{C}$ for $24 \mathrm{~h}$. The polymer $1 \mathrm{~d}$ was obtained as a yellow powder that was soluble in common solvents, such as benzene, tetrahydrofuran (THF), and chloroform.

The molecular weight of the polymer was measured by GPC, the terminal vinyl group analysis based on ${ }^{1} \mathrm{H}$ NMR, and the bromine analysis on the other terminal to be $2.6 \times 10^{3}, 2.7 \times 10^{3}$, and $2.9 \times 10^{3}$, respectively: They agreed with each other and supported the polymer structure. The relatively low molecular weight of $\mathbf{1 d}$ in comparison with that of $\mathbf{1 b}$ is probably caused by the bulky structure of the monomer 5 . The poly(phenylenetrans-vinylene) structure was supported by the UV absorption of $\lambda_{\max }=287 \mathrm{~nm} \quad\left(\varepsilon=2.4 \times 10^{4} \mathrm{M}^{-1} \mathrm{~cm}^{-1}\right)$ and $\lambda_{\text {shoulder }}=c a .350 \mathrm{~nm}\left(\varepsilon=c a .1 \times 10^{4} \mathrm{M}^{-1} \mathrm{~cm}^{-1}\right)$, and the fluorescence at $453 \mathrm{~nm}$ (excitation at $287 \mathrm{~nm}) .^{2 b, 9}$ The primary structure, which is essential for a ferromagnetic spin alignment, was established through the polymerization of the bromostyrene derivative with the palladium catalyst.

An irradiation on a solution of $\mathbf{1 d}$ with a high-pressure xenon arc lamp for $1 \mathrm{~min}$ at room temperature turned the solution from pale yellow to bluish brown. The color change was also observed for the cast film of 1d on a quartz plate. For example, the UV/Vis spectral change of the 1d thin film after the photo-irradiation for $1 \mathrm{~min}$ supported the efficient radical generation in the solid state (Figure 1). The photo-irradiation brought about the new absorption at $c a .700 \mathrm{~nm}$ attributed to the 2,6-di-t-butylphenoxyl radical and a bathochromical shift of the skeleton from $\lambda_{\max }=278 \mathrm{~nm}$ to $\mathrm{ca}$. $480 \mathrm{~nm}$; the latter supported the polyphenoxyl formation conjugated with the poly(phenylenevinylene) skeleton.

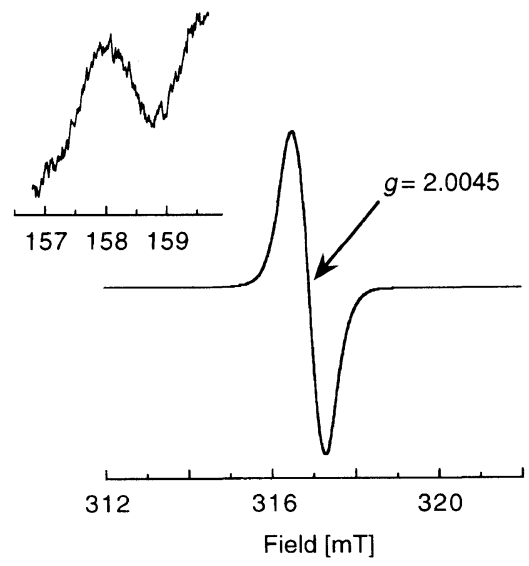

Figure 3. Solution ESR spectrum of the photochemically generated polyradical 1a in a 2-methyltetrahydrofuran at room temperature. Inset: $\Delta M_{\mathrm{s}}= \pm 2$ spectrum for $1 \mathrm{a}$ in a frozen 2-methyltetrahydrofuran glass at $10 \mathrm{~K}$.

The IR spectral change given in Figure 2 also supported the photochemical cleavage of the oxalate derivative. The irradiation for a few min on the film cast on a $\mathrm{KBr}$ plate, induced rapid decrease in the absorption at $1763 \mathrm{~cm}^{-1}$ which was attributed to the stretching vibration of carbonyl group.

The photo-irradiation of a 2-methyltetrahydrofuran solution of $1 \mathbf{d}$ for $1 \mathrm{~min}$ at $200-300 \mathrm{~K}$ gave a broadened ESR peak at $g=2.0045$ assigned to the oxyradical center ${ }^{7}$ in the $\Delta M_{\mathrm{s}}= \pm 1$ region (Figure 3 ), supporting the formation of 1a. Taking into account the strong absorption of the poly(phenylenevinylene) skeleton in the UV region, the radical formation through photo-cleavage of the bisaryloxalate group was successful. ${ }^{10} \mathrm{~A}$ frozen 2-methyltetrahydrofuran glass of 1a gave a $\Delta M_{\mathrm{s}}= \pm 2$ forbidden transition at $g=4$ (Inset of Figure 3) which is ascribed to a triplet species. This indicates a ferromagnetic spin-alignment between the pendant phenoxyl radicals through the poly(1,2-phenylenevinylene) skeleton.

In conclusion, a $\pi$-conjugated poly(1,2-phenylenevinylene) functionalized with the photolysis group, poly[4$\left(3^{\prime}, 5^{\prime}\right.$-di- $t$-butyl-4'-(2' $, 4^{\prime \prime}, 6^{\prime \prime}$-tri-t $t$-butylphenyloxalato $)$ phenyl)-1,2-phenylenevinylene], 1d was synthesized. The polymer photochemically generated phenoxyl radicals on its pendant sites due to irradiation by white light in the solid phase even at low temperature; the polyradical displays a ferromagnetic interaction between the pendant phenoxyl radicals through the $\pi$-conjugated skeleton.

\section{EXPERIMENTAL AND NOTE}

\section{Synthetic Procedures}

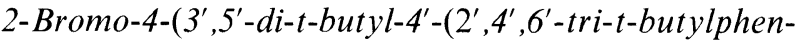
$y l$ oxalatophenyl)-toluene (4). 2-Bromo-4-(3',5'-di-t-butyl-4'-hydroxyphenyl)toluene $(3)^{2 \mathrm{~b}}(12.9 \mathrm{~g}, 34.4 \mathrm{mmol})$ was reacted with 2,4,6-tri-t-butylphenyloxalyl chloride ${ }^{4}$ $(12.1 \mathrm{~g}, 34.4 \mathrm{mmol})$ in triethylamine $(194 \mathrm{ml})$ at room temperature for a day. Triethylamine was removed under a reduced pressure, and hexane was added to the residue to filter off triethylammonium chloride. Recrystallization from ethanol gave needle-like crystals of $4(5.2 \mathrm{~g})$. Yield $22 \%$. mp 154.2-155.2 ${ }^{\circ} \mathrm{C}$, IR ( $\mathrm{KBr}$ pellet, $\left.\mathrm{cm}^{-1}\right)$ : $2969-2870\left(v_{\mathrm{C}-\mathrm{H}}\right), 1763\left(v_{\mathrm{C}=\mathrm{o}}\right) ;{ }^{1} \mathrm{H}$ NMR $(270 \mathrm{MHz}$ in $\left.\mathrm{CDCl}_{3}\right): \delta 7.33-7.29(\mathrm{~m}, 7 \mathrm{H}, \mathrm{Ar}), 2.45\left(\mathrm{~s}, 3 \mathrm{H}, \mathrm{CH}_{3}\right)$, 
$1.36-1.34(\mathrm{~s}, 45 \mathrm{H}, t-\mathrm{Bu}) ;{ }^{13} \mathrm{C}$ NMR $(68 \mathrm{MHz}$ in $\left.\mathrm{CDCl}_{3}\right): \delta 158.69,148.30,147.39,145.18,142.91,141.21$, $140.75,137.62,136.78,131.01,130.97,126.19,125.44$, 125.26, 123.64, 35.72, 31.62, 31.54; $\mathrm{MS} m / z\left(\mathrm{M}^{+}, \mathbf{M}^{+}+2\right)$ calcd for $\mathrm{C}_{41} \mathrm{H}_{55} \mathrm{BrO} 690.35$, found 690, 692 .

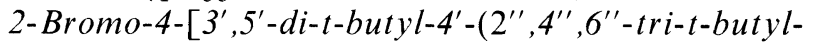
phenyl)oxalato]styrene (5). $4(0.81 \mathrm{~g}, 4.34 \mathrm{mmol})$ was dissolved in $\mathrm{CCl}_{4}(44 \mathrm{ml}) . N$-Bromosuccinimide (NBS) $(0.812 \mathrm{~g}, 4.56 \mathrm{mmol})$ and a trace of $2,2^{\prime}$-azobisisobutyronitrile (AIBN) were suspended to the $\mathrm{CCl}_{4}$ solution of $4(3.0 \mathrm{~g}, 4.34 \mathrm{mmol})$ and refluxed until the succinimide floated on the solution. The mixture was cooled to room temperature and filtered off. After the filtrate was evaporated, benzene $(18.7 \mathrm{ml})$ and triphenylphosphine $(4.34$ mmol) were added, and the resulting solution was stirred at $50^{\circ} \mathrm{C}$ for $7 \mathrm{~h}$. After evaporation, the product was purified on a silica gel column with ethyl acetate/ hexane $(1: 9)$ as an eluent to give the phosphonium salt $(3.3 \mathrm{~g})$. The phoshonium salt was suspended in the mixture of $25 \%$ formaldehyde $(32.1 \mathrm{ml})$, benzene $(32.3 \mathrm{ml})$, and $\mathrm{H}_{2} \mathrm{O}(9.6 \mathrm{ml})$, and the suspension was stirred for $1 \mathrm{~h}$. $5 \mathrm{~N}-\mathrm{NaOH}$ aqueous solution $(2.2 \mathrm{ml})$ was added dropwise over $10 \mathrm{~min}$ to the suspension with stirring at room temperature. The mixture was stirred for $1.5 \mathrm{~h}$ and extracted with benzene. The extract was washed with water, dried over anhydrous sodium sulfate, and then evaporated. Triphenylphosphine oxide in the crude product was removed by a silica gel column with chloroform/hexane $(1: 1)$ as an eluent. After evaporation, the products was recrystallized with hexane to yield $\mathbf{5}$ $(1.1 \mathrm{~g})$ as a white powder: Yield $49 \%, \mathrm{mp} 208-209^{\circ} \mathrm{C}$; IR ( $\mathrm{KBr}$ pellet, $\left.\mathrm{cm}^{-1}\right): 3088-2965\left(v_{\mathrm{C}-\mathrm{H}}\right), 1759\left(v_{\mathrm{C}=\mathrm{o}}\right)$, $1624\left(v_{\mathrm{C}=\mathrm{c}}\right) ;{ }^{1} \mathrm{H}$ NMR $\left(270 \mathrm{MHz}\right.$ in $\left.\mathrm{CDCl}_{3}\right): \delta 7.76$ 7.39 (m, 7H, Ar), 7.10 (dd; $J=17.3,11.1 \mathrm{~Hz}, 1 \mathrm{H}$, vinyl), 5.75 (d, $J=17.8 \mathrm{~Hz}, 1 \mathrm{H}$, vinyl), 5.39 (d, $J=11.2 \mathrm{~Hz}, 1 \mathrm{H}$, vinyl), $1.46(\mathrm{~s}, 18 \mathrm{H}, t$-Bu), $1.42(\mathrm{~s}, 18 \mathrm{H}, t-\mathrm{Bu}), 1.34(\mathrm{~s}$, $9 \mathrm{H}, t-\mathrm{Bu}) ;{ }^{13} \mathrm{C} \mathrm{NMR}\left(68 \mathrm{MHz}\right.$ in $\left.\mathrm{CDCl}_{3}\right): \delta 31.9(t-\mathrm{Bu})$, 36.1 $(t-\mathrm{Bu}), 116.6\left(-\mathrm{CH}=\mathrm{CH}_{2}\right), 123.4(\mathrm{Ph}), 123.9(\mathrm{Ph})$, $125.3(\mathrm{Ph}), 126.1(\mathrm{Ph}), 126.7(\mathrm{Ph}), 131.2(\mathrm{Ph}), 135.1$ $\left(-\mathrm{CH}=\mathrm{CH}_{2}\right), 136.1(\mathrm{Ph}), 137.0(\mathrm{Ph}), 141.0(\mathrm{Ph}), 142.0$ (Ph), $142.9(\mathrm{Ph}), 144.9(\mathrm{Ph}), 147.3(\mathrm{Ph}), 148.0(\mathrm{Ph}), 158.4$ (carbonyl); $\mathrm{MS} m / z\left(\mathrm{M}^{+}, \mathrm{M}^{+}+2\right.$ ) calcd for $\mathrm{C}_{42} \mathrm{H}_{55} \mathrm{BrO}$ 702.35, found 702, 704; Anal. Calcd for $\left(\mathrm{C}_{42} \mathrm{H}_{55} \mathrm{BrO}_{4}\right)$ : C, $71.7 \%$; H, 7.9\%; Br, $11.4 \%$. Found: C, 71.7\%; H, $7.8 \% ; \mathrm{Br}, 11.4 \%$.

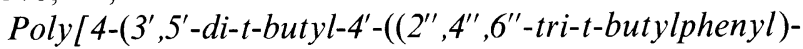
oxalatophenyl))-1,2-phenylenevinylene] (1d). 5 (500 mg) was polymerized in the presence of $\mathrm{Pd}(\mathrm{OAc})_{2}(0.071$ $\mathrm{mmol})$, tri-o-tolylphosphine $(0.014 \mathrm{mmol})$, and triethylamine $(3.55 \mathrm{mmol})$, in the DMF solution $(49.7 \mathrm{ml})$ at $100^{\circ} \mathrm{C}$ for $12 \mathrm{~h}$ under nitrogen. The catalyst was removed with a polystyrene gel column and was purified by reprecipitation from chloroform into methanol to give a yellow powder $(210 \mathrm{mg})$. Yield $42 \mathrm{wt} \%$, IR ( $\mathrm{KBr}$ pellet, $\left.\mathrm{cm}^{-1}\right): 2965-2876\left(v_{\mathrm{C}-\mathrm{H}}\right), 1763\left(v_{\mathrm{C}=\mathrm{O}}\right), 963$ $\left(\delta_{\text {trans vinylene }}\right) ;{ }^{1} \mathrm{H}$ NMR $\left(270 \mathrm{MHz}\right.$ in $\left.\mathrm{CDCl}_{3}\right): \delta$ 7.78-6.98, 1.54-1.26; Anal. Found: C, $77.55 \%$; $8.45 \% ; \mathrm{Br}, 2.63 \%$.

\section{Measurements}

The ESR, IR, NMR, mass, UV/Vis, and fluorescence spectra were measured with a JEOL RE-2XG at X-band, a JASCO FT-IR 5300, a JEOL NMR 500 , a Shimadzu GC-17A, a JASCO $\pi$-550, and a JASCO FP-770 spectrometer, respectively. The molecular weight of the polymer was estimated with a TOSOH LS-8000 molecular weight analyzer using a polystyrene gel column and THF as an eluent.

Acknowledgments. This work was partially supported by a Grant-in-Aid for Scientific Research (Nos. 09305060 and 277/08246101) from the Ministry of Education, Science, Sports and Culture of Japan.

\section{REFERENCES AND NOTE}

1. Reviews: (a) H. Iwamura and N. Koga, Acc. Chem. Res., 26, 346 (1993); (b) A. Rajca, Chem. Rev., 94, 871 (1994); (c) J. S. Miller and A. J. Epstein, Angew. Chem. Int. Ed. Engl., 33, 385 (1994); (d) H. Nishide, Adv. Mater., 7, 937 (1995); (e) M. Kamachi, in "Functional Monomers and Polymers," K. Takemoto, R. M. Ottenbrite, and M. Kamachi, Ed., Marcel Dekker, New York, N.Y., 1997, Chapter 5.

2. Recent papers: (a) Kajiwara, K. Aramata, and M. Kamachi, Polym. J., 26, 215 (1994); (b) H. Nishide, T. Kaneko, T. Nii, K. Katoh, E. Tsuchida, and P. M. Lahti, J. Am. Chem. Soc., 118, 9695 (1996); (c) Y. Miura, T. Issiki, Y. Ushitani, Y. Teki, and K. Itoh, J. Mater. Chem., 6, 1745 (1996); (d) H. Nishide, Y. Hozumi, T. Nii, and E. Tsuchida, Macromolecules, 30, 3986 (1997); (e) A. Rajca, K. Lu, and S. Rajca, J. Am. Chem. Soc., 119, 10335 (1997); (f) A. Rajca, J. Wongsriratanakul, S. Rajca, and R. Cerny, Angew. Chem. Int. Ed., 1998, 1229 (1998).

3. A. A. Ovchinnikov, Theoret. Chim. Acta, 47, 297 (1978).

4. D. A. Modarelli and P. M. Lahti, J. Am. Chem. Soc., 114, 6329 (1991); P. M. Lahti, D. A. Modarelli, F. C. Rossitto, A. L. Inceli, A. S. Ichimura, and S. Ivatury, J. Org. Chem., 61, 1730 (1996).

5. R. Kalgutkar, A. S. Ionkin, L. D. Quin, and P. M. Lahti, Trtrahedron Lett., 35, 3889 (1994).

6. Y. Togo, N. Nakamura, and H. Iwamura, Chem. Lett., 1201 (1991).

7. F. C. Rossitto and P. M. Lahti, Macromolecules, 26, 6308 (1993).

8. M. Takahashi, H. Nishide, E. Tsuchida, and P. M. Lahti, Chem. Mater., 9, 11 (1997).

9. K. Chino, T. Takata, and T. Endo, Macromolecules, 30, 6715 (1997).

10. The yield of the polyradical 1a generated upon the photolysis of the cast film of 1d was estimated to be $c a .50 \%$ of the accessible number of radical spins, assuming that a self-filtering effect due to strong UV-Vis absorbance of $1 \mathrm{~d}\left(\varepsilon=(1-2) \times 10^{4} \mathrm{~cm}^{-1} \mathrm{M}^{-1}\right.$ in the region $250-350 \mathrm{~nm}$ ) only allows photolysis to a depth of ca. $0.2 \mu \mathrm{m}$ of the cast film surface and that two radicals are generated per the oxalate group through the photolytic cleavage, one pendant-attached radical plus one leaving group radical. 